\title{
REPRESENTASI KELAS BAWAH PADA TOKOH PUNAKAWAN DALAM KOMIK KARYA TATANG S.
}

\author{
Binar Murgati Pardini \\ Irsyad Ridho \\ Saifur Rohman
}

\begin{abstract}
Abstrak. Penelitian ini bertujuan untuk merepresentasikan kelas bawah pada tokoh Punakawan dalam komik karya Tatang S. Penelitian ini menggunakan metode deskriptif kualitatif yaitu menjabarkan gambaran cerita secara lengkap. Sema banyak dua puluh buah judul komik penelitian ini coba menafsirkan tanda- tanda kekelasbawahan yang ada di dalamnya. Dengan menggunakan konsep- konsep teoritis yang mencakup pola fungsi aktan, representasi dalam kajian budaya, pendekatan semiologi Rolland Barthes, konsep kelas bawah dalam tokoh Punakawan. Skripsi ini mengajukan kesimpulan bahwa peranperan tokoh punakawan dalam komik Tatang merupakan representasi konstruksi kelas bawah dalam kondisi masyarakat dimana komik tersebut dibuat. Penelitian ini menemukan beberapa ciri kelas bawah yang ditandai dalam beberapan hal yang terkategorisasi pada pola kemunculan hantu, kisah asmara, kisah kepahlawanan, dan humor yang ditawarkan dalam cerita.
\end{abstract}

\section{Kata kunci: Representasi, Kelas Bawah, Punakawan.Tatang S.}

\section{PENDAHULUAN}

Anggapan bahwa komik hanya merupakan buku bacaan waktu senggang yang tak bermakna dan bercita rasa rendah nampaknya masih melekat dalam ranah kajian kesustaraan.Komik tidak dipandang sebagai sebuah kajain kultural yang bermakna, melainkan secara diskrimintif cenderung dianggap sebagai sebuah entitas ideologis yang subversif dan berbahya.Terbukti, dalam ranah kajian dunia kesusatraan Indonesia masih jarang mengambil komik menjadi salah satu objek kajiannya.Padahal, seperti halnya objek kajian sastra lainnya, komik juga dibangun dari unsur- unsur naratif dan merupakan bagian dari produk budaya dalam sebuah tatanan masyarakat.

Komik merupakan suatu bentuk seni populer yang hidup dalam masyarakat dan menjadi merata di seluruh dunia. Sebagai salah satu artefak peradaban modern, tercatat bahwa komik mulai muncul dalam kehidupan masyaraat Indonesia pada tahun 1930, tahun yang sama ketika Amerika mulai dilanda demam komik dan Great Depression.

Disebutkan oleh Zeffry Alkatiri dalam Pasar Gambir, Komik Cina \& Es Shanghai Sisik Melik Jakarta 1970-an, bahwa sampai akhir 1970-an di Indonesia telah hadir sekitar 50 orang komikus yang mebuat komik silat (Zeffry Alkatiri, 2010: 81). Maka, wajar saja jika sejauh ini kajian ilmiah mengenai komik yang keberadaanya minim itu lebih banyak mengambil objek kajian kepada komik yang lahir di kisaran 1970-an hingga 1980-an atau pada komik strip yang terbit rutin di dalam koran. Hal tersebut disebabkan karena jumlah produksi komik saat itu sangatlah produktif. 
Hingga pada era 1980-an hingga 1990-an produksi komik Indonesia mulai meredup diakibatkan adanya invasi komik manga yang juga dijual murah di toko- toko buku besar seperti Gramedia.Namun ditengah kehancuran pasar komik Indonesia Tatang Suhenra muncul dan mencipta pasarnya sendiri. Nama Tatang Suhenra tak akan asing terdengar sebagai bagian dari perkembangan komik di Indonesia. Khususnya pada generasi yang besar dan tumbuh pada kisaran tahun 80-an hingga 90-an akhir. Tatang Suhenra atau yang lebih sering dikenal dengan sebutan Tatang $S$ ini cukup banyak melahirkan komik- komik yang turut mewarnai khazanah perkomikan di Indonesia. Dengan tokoh Punakawan yaitu Petruk, Gareng, Bagong dan Semar, ia menyuguhkan cerita- cerita yang erat kaitannya dengan kehidupan masyarakat kelas bawah.

Karya- karya Tatang diterbitkan secara masal melalui penerbit kecil di bilangan Pasar Senen, Jakarta dan dijual dengan harga yang sangat murah mulai dari Rp. 500 sampai dengan Rp.2000. Buku komiknya juga dicetak secara sederhana dengan cara cetak stencil dan secara kontinu buku Tatang diterbitkan dan dijajakan kepada masyarakat.

Menurut Henry Ismono salah seorang pengamat komik dalam artikel yang diterbitkan pada situs internetnya, Tatang S. termasuk komikus yang mecoba bertahan dengan membuat komik petruk gareng dengan format sederhana di tengah redupnya komik di Indonesia pada tahun 1980-an. Komiknya ini dijual murah dengan didistribusikan langsung ke SDSD lewat penjual mainan. Tidak perlu bicara soal kualitas. Komik dengan penerbit kebanyakan Gultom Agency itu, dibuat tipis dengan kertas buram. Tatang pun membuat kisah sederhana, yang terkadang disesuaikan dengan tren di masa itu (Henry Ismono, 2015).

Tak dapat disangkal bagaimana pun wacana yang berkembang mengenai komik, komik buatan Tatang S. tetaplah bagian dari produk kultural yang bermakna yang didalamnya mereperesentasikan konstruksi- konstruksi yang terbangun dalam sebuah masayarakat.Tak ingin terjebak pada dikotomi avant garde sastra atau sastra kitch, menurut hemat peneliti komik ini juga merupakan bagian dari dokumen budaya yang mesti dirawat.

Sebuah karya sastra merupakan bentuk gambaran nyata sebuah masyarakat.Dalam hal ini cerita yang diangkat dalam komik Petruk karya Tatang S. menjadi salah satu karya yang turut menjadi gambaran sebuah tatanan masyarakat.Komik ini sendiri merupakan bagian dari budaya populer dalam pengertian budaya masal yang mengambil pasar kalangan kelas bawah.Mengingat harga murah yang dibandrol, maka tak heran jika Tatang memilih tokoh punakwan yang diadaptasi dari tokoh pewayangan jawa.Sebagai simbol kehidupan masyarakat biasa dan dimodifikasi ke dalam cerita berlatar kekinian.

Seno Gumira Ajidarma menjelaskan Punakawan merupakan sosok karikatural dalam pewayangan jawa sebagai representasi rakyat kelas bawah yang dalam pewayangan berperan menghibur, mengasuh, membimbing, dan menjaga para ksatria yang berkuasa, yang pada masa krisis rupanya para punakwan ini dianggap sahih menggunakan cara- cara ekstrem (Seno Gumira Ajidarma, 2012:356). Namun Punakawan dalam Komik buatan Tatang tidak lagi menjadi ajudan ataupun pengasuh dari para ksatria yang maha sempurna, melainkan mereka hadir untuk dirinya sendiri dan tidak melayani siapapun.

Sosok pewayangan jawa dikomodifikasi ke dalam sebuah komik yang dianggap sebagai budaya populer dan tidak serius, padahal wayang merupakan bagian dari ritus budaya jawa yang sakral. Uniknya dalam komik Tatang S. punakawan digambarkan sebgai 
pemuda pengangguran yang hidup di daerah pinggiran kota Jakarta dan fasih berlogat betawi.

Judul penelitian Representasi Kelas Bawah pada Tokoh Punakawan dalam Komik Petruk Gareng karya Tatang Suhenra ini sengaja dipilih oleh peneliti karena belum terdapat kajian dalam bidang ilmu sastra atau lainya yang terkait pada objek komik Petruk Gareng karya Tatang Suhenra. Hal tesebut menjadi salah satu alasan yang dianggap cukup penting mengingat kajian mengenai komik belum signifikan jumlahnya dibandingkan jumlah komik yang beredar sejak tahun 1930-an. Belum lagi, penelitian ini mengambil objek sebuah komik yang merupakan komoditi yang dijual secara masal dengan harga murah ditengah krisisnya jagat komik Indonesia yang tengah berjuang melawan dominasi komik manga yang membanjiri pasar dan secara perlahan namun pasti menendang komikus di negeri ini.

Berdasarkan berbagai alasan tersebut, inti dari penelitian ini pada dasarnya ingin membongkar bentuk- bentuk representasi kelas bawah yang ada pada masyarakat Indonesia dalam hubungannya pada cerita dalam komik Petruk karya Tatang S. Dan membuktikan pernyataan bahwa sebuah karya dalam hal ini cerita komik rakyat menjadi repersentasi nyata sebuah kehidupan masyarakat.

\section{METODE PENELITIAN}

Penelitian ini menggunakan metode penelitian deskriptif-kualitatif.Penelitian kualitatif adalah penelitian tentang riset yang bersifat deskriptif dan cenderung menggunakan analisis. Proses dan makna (perspektif subyek) lebih ditonjolkan dalam penelitian kualitatif. Landasan teori dimanfaatkan sebagai pemandu agar fokus penelitian sesuai dengan fakta di lapangan.Selain itu landasan teori juga bermanfaat untuk memberikan gambaran umum tentang latar penelitian dan sebagai bahan pembahasan hasil penelitian.

\section{HASIL PENELITIAN}

Dari hasil analisis sebelumnya didapati beberapa ciri yang menandai adanya representasi kelas bawah pada komik Tatang S. Pada penelitian ini ditemukan ciri kelas bawah yang berulang dalam keduapuluh komik yang digunakan.

Dibawah ini merupakan analisis representasi kelas bawah dalam tiap ciri yang telah ditemukan sebelumnya dalam pencacahan data pada fungsi aktannya dan hasil dari pendekatan semiotik dalam pemaknaan tataran kedua. Ciri- ciri kekelasbawahan tersebut dikategorisasikan pada empat buah sub bab yang dipaparkan sebagai berikut.

\section{Hantu Sebagai Simbol Kelas Bawah yang Tergusur}

Hampir pada tiap cerita dalam komik- komik Tatang berlatar tempat di ruang terbuka yaitu jalanan kampung Tumaritis.Biasanya pada adegan pembuka cerita digambarkan tokoh Petruk sedang berjalan di seputaran desa Tumaritis sambil menghayalkan sesuatu.Sebagai pemuda yang tidak memiliki pekerjaan yang jelas tokoh Petruk dan Gareng punya banyak waktu luang untuk sekedar jalan- jalan tak tentu arah di siang hari dan cerita dapat tersusun dengan pertemuannya atau penemuannya di jalanan kampunya itu.Sementara pada malam hari adegan berjalan di jalanan kampung juga masih 
dapat ditemui mengingat budaya kampung yang masih menerapkan sistem Siskamling untuk tugas jaga malam yang juga biasa dilakukan Petruk dan temanya Gareng.

Ada beberapa kecenderungan cerita yang dapat dilihat dari latar tempat yang disuguhkan dalam komik.Misalnya, pada kisah yang yang bertema bukan hantu biasanya lebih bebas memnggambarkan latar tempat misalnya jalanan kampung yang dipenuhi rumah atau tempat- tempat wisata yang ramai pengunjung.Tidak seperti pada cerita yang bukan bertema hantu, latar cerita ditampilkan di tempat yang memungkinkan sosok hantu muncul disana atau dalam kategori "tempat angker." Dari dua puluh buah komik yang digunakan dalam peneliatian ini saja ditemukan sebnagak lima belas komik yang secara langsung menampilkan latar kampung yang lebih mirip hutan karena banyak ditumbuhi pohon- pohon besar semenatara bangunan seperti rumah hanya sedikit terdapat.

Tempat yang dapat ditandai sebagai tempat angker dapat berupa jalanan sepi atau dibawah pepohonan rindang Kampung Tumaritis. Tempat- tempat tersebut memungkinkan adanya kemunculan mahluk halus yang dalam peradaban modern cerita semacam itu hanya dianggap omong kosong belaka.Maka citra kampung yang jauh dari kesan modern memungkinkan sosok hantu dapat diletakan dan diterima oleh pembaca.Maka Kampung dimana tempat angker berada merupakan ciri dari masyarakat kelas bawah yang mengkonstruksikan masyarakat yang tidak "modern" dan masih menggunakan nilai- nilai lama beserta kisah- kisah di luar nalar yang menjadi wajar dalam konteks ruang tersebut.

Model kemunculan hantu dapat dipengaruhi dari dua hal utama yaitu motif pembalasan dendam dan persentuhan dengan tempat angker.Keduanya mungkin terjadi bersamaan, artinya meski adanya motif pembalasan dendam, nuansa angker tetap dibangun dalam kemunculan mahluk sosok hantu.Seperti dalam komik berjudul Dendam Mayat Busuk yang bercerita tentang pembalasan dendam sesosok mayat yang keluar dari dalam kubur.Cerita tersebut diawali dengan deskripsi suasana malam yang sepi dan mencekam dan dari sebuah kuburan keluarlah sesosok mayat yang sudah membusuk.

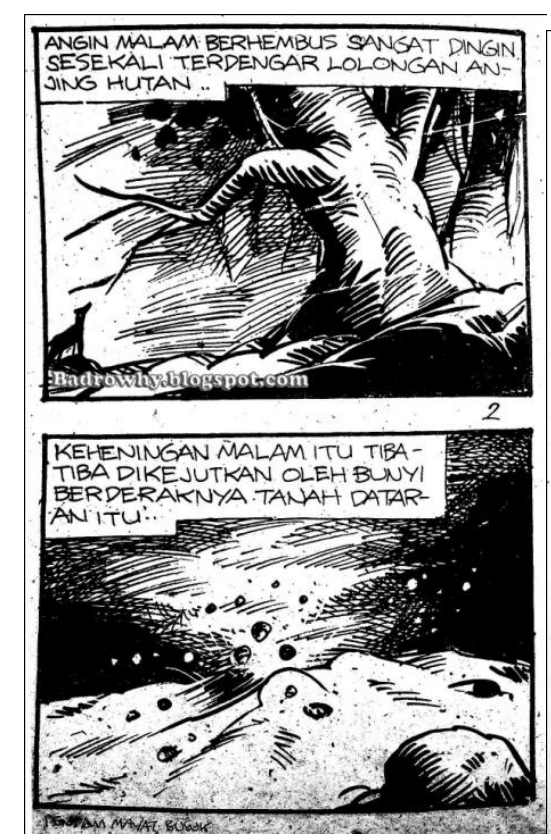

Gambar 4.31
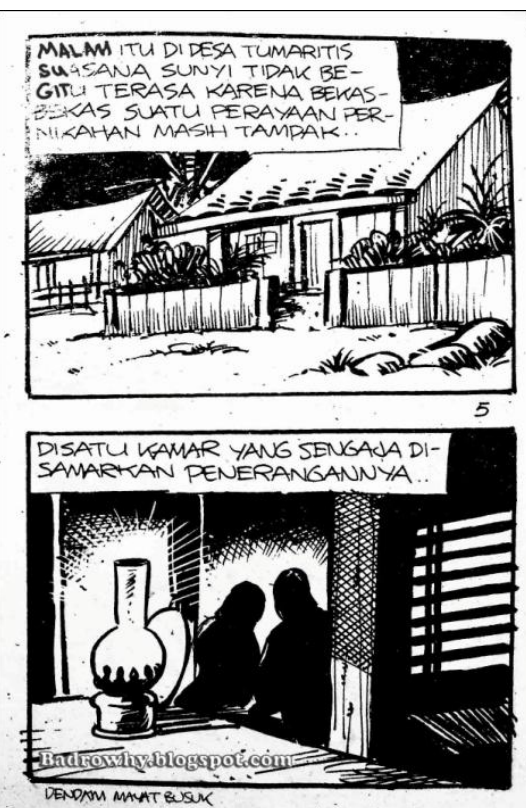

Gambar 4.32 
Pada panel diatas menggambarkan bagaimana closure subjek ke- subjek berlangsung untuk membangun suasana mencekam pada awal cerita.Dua panel itu hanya dilengkapi dengan narasi terlihat lokasi yang digambarkan ditumbuhi pohon besar dan terdapat anjing yang melolong.Kemudian di paenl selanjutnya digambarkan bahwa tanah mulai bergerak karena terdorong sesuatu dari bawah.

Kemudian masih dalam cerita yang sama, terdapat narasi suasana kembali namun kali ini subjek yang digambarkan bukan lagi tempat anker seperti pemakaman melainkan sebuah kampung yang sepi dan pada panel berikutnya subjek beralih ke sebuah kamar dengan penerangan lampu minyak yang temaram. Dalam narasinya, masih menjelaskan tentang malam yang sepi sebagi simbol bahwa latar suasana yang seperti itu merupakan suasana yang memungkinkan cerita horor ini dapat berlangsung.

\section{Kisah Asmara Sebagai Penanda Poisisi Kelas Bawah dalam Hierarki Kelas}

Sebagai bagian dari budaya pop persoalan asmara tentu menjadi tema yang sering digunakan sebagai bumbu cerita. Begitu pula pada komik Tatang, soal asmara dari para pelaku ceritanya dibawakan sebagai unsur pembangun cerita. Ada yang khusus membahas cinta sebagai tema dalam satu cerita ada pula yang hanya menjadikan persoalan cinta sebagai unsur di dalam cerita. Dari dua puluh buah judul komik yang digunakan terdapat enam belas buah cerita yang memasukan unsur cinta dan dua cerita diantaranya merupakan cerita yang khusus membahas masalah asmara yaitu dengan judul Jodoh Lah Ya dan Berkunjung Ke Rumah Desi. Hal tersebut ditunjukan dengan percakapan anatar Petruk dan Ani seperti dibawah ini:

Petruk : Bukananya gak cinta aye sama dek Ani, tapi rasa nya hubungan kita nggak seimbang.

Ani : Apa maksud bang Petruk!

Petruk : Dik Ani gak pantas punya pacar kayak abang karena abang orang gak punya alias kere!

Pada cerita Jodoh Lah $\mathrm{Ya}$ dijelaskan bagaimana hubungan Petruk dan Ani harus putus karena tidak adanya restu dari orang tua Ani.Seperti pada kutipan percakapan diatas Petruk berasal dari kalangan sosial kelas bawah yang tidak sepadan dengan Ani yang merupakan anak dari seorang yang kaya raya.Padahal hubungan kekasih secara mendasar hanya bersumber pada rasa cinta diantara kedua belah pihak tanpa embel- embel apapun.Namun hal tersebut tak lagi menjadi dasar berlangsungya sebuah hubungan.

Denotasi yang menyatakan teks Jodoh Lah $\mathrm{Ya}$ adalah persoalan cinta yang terlarang menghasilkan konotasi bahwa cinta merupakan sebuah investasi jangka panjang yang masing- masing pasangannya harus memiliki kualifikasi tertentu seperti kelas sosial dan kekayaan.Dari konotasi tersebut memunculkan petanda baru pada lapis makna kedua yaitu adanya mitos bahwa hubungan cinta adalah hasil kesepakatan tentang status kelas sosial antara kedua belah pihak.

Hubungan cinta pada teks Komik 1 menunjukan adanya oposisi biner antara kayadan miskin dimana hal tersebut menjadi kategori utama dalam penentuan calon pasangan.Nampak melalui petanda dalam teks bahwa terdapat kesenjangan sosial dalam 
konstruksi wacana mengenai cinta dalam masyarakat yang direpresentasi dalam komik karya Tatang Suhenra.

Dapat ditarik kesimpulan dalam hubungan asmara antara perempuan dan laki- laki sudah menjadi sebuah mitos dalam masyarakat bahwa perempuan harus memperhitungkan tingkat kemapanan ekonomi dari pasangan prianya baru setelah perkara tersebut terpenuhi hubungan asmara dapat berlanjut ke jenjang berikutnya. Dan dari kesimpulan tersebut juga menunjukan bahwa jika pihak pria memang berasal dari golongan kelas atas maka ia berhak menentukan pasangan yang ia mau.

\section{Kisah Kepahlawanan Sebagai Sikap Moral Kelas Bawah}

Dalam kisah pewayangan kuartet punakawan digambrakan sebagai representasi rakyat kecil ditengah kehidupan para ksatria dan raja- raja.Kata punakawan sendiri sebenrnya merupakan bentuk salah kaprah dari kata panakawan, pana berarti terang, menerangi, sedangkan kawan memiliki arti sejawat. Berdasarkan Kamus Besar Bahasa Indonesia (2006) kata Punakawan memiliki arti sebagai "pelayan atau pegawai raja atau bangsawan pada zaman dahulu." Disadari atau tidak menurut tokoh kwartet Semar, petruk, Gareng dan Bagong adalah tokoh yang ditunggu- tunggu kemunculannya dalam sebuah pertunjukan wayang pada bagian yang disebut sebagai Goro-goro. Mereka hadir dengan konflik yang lebih mudah dipahami dan rasional karena menyangkut mengenai kehidupan sehari- hari dan dibawakan dengan sangat menghibur dan penuh humor.

Berbeda pada komik Tatang Suhenra, meski menampilkan sosok yang sama yaitu para Punakwan, namun mereka hadir untuk dirinya sendiri tidak untuk mengabdi kepada siapapun. Komik Tatang melepaskan fungsi Punakawan dari atmosfer pewayangan dan memindahkannya pada ruang yang sama sekali berbeda yaitu kehidupan masa kini. Mereka tinggal di sebuah kampung beranam Desa Tumaritis yang nama tersebut bukan smebarang digunakan Tatang namun memang keberadaanya memang terdapat dalam kisah pewayangan.

Tak hanya melepaskan perannya sebagai abdi dari para raja, punakwan versi Tatang dalam beberapa seri cerita juga menjelma pahlawan super yang dapat memberantas segala macam masalah mulai dari monster, orang jahat, atau bahkan mahluk luar angkasa. Dengan gaya konyol dan cenderung aneh mereka bisa mengubah diri sebagai pahlawan super a la Amerika seperti Batman, Hulk, Megaloman, dan He-Man dan beberapa adaptasi lain yang disesuaikan dengan budaya populer yang sedang berkembang di masyarakat. Dalam dua puluh judul cerita komik Tatang yang digunakan dalam penelitian ini terdapat tiga buah cerita yang bertemakan pahlawan super secra khusus yang diadaptasi dari pahalwan super yang sedang populer yaitu He-Man Tumaritis:Adu Jago (Jaya Agency), Petruk Jadi HULK: Warisan (Jaya Agency), dan Petruk Megaloman.

Pada judul He-man Tumaritis: Adu Jago, Petruk berperan sebagi pahlawan super yang menolong seorang wanita dari gerombolan penjahat yang menculiknya. Wanita tersebut ialah kekasih dari Gareng, dan Gareng meminta pertolongan kepada Petruk yang merupakan seorang Hi-Man yang berkekuatan super untuk menyelamatkan kekasihnya tersebut dari para penculik yang bermarkas di sebuah bukit. Maka dengan segera Petruk sang Hi-man Tuamritis pergi ke bukit tersebut dan menumpas habis pasukan kejahtan dan pemimpinnya dengan kekuatan super yang dimilikinya. Di akhir cerita Petruk berhasil membawa kembali kekasih Gareng dan Gareng pun berterima kasih dan tak meragukan kekuatan Petruk yang perkasa dimana dapat menumpas seluruh pasukan kejahatan. 
Sosok Hi-Man Tumaritis sendiri bisa dikatakan merupakan upaya adaptasi Tatang Suhenra pada tokoh He-Man yang berasalh dari Amerika.Sosok pahlawan super versi Amerika itu diciptakan oleh seorang bernama Mattel yang awalanya merupakan salah satu ikon komik yang diterbitkan oleh penerbit komik terkemuka DC Comics.Pahlawan super yang merupakan ksatria penjelmaan dari Pangeran Adam dan kembaran She-Ra yang bertugas melindungi kastil Grayskull dari pasukan jahat Skeletor itu pernah ditayangankan seri animasinya di Indonesia. Pada sekitar akhir tahun 1980-an serial animasi berjudul $\mathrm{He}$ Man And The Master Of the Universe pernah tayang di TVRI.
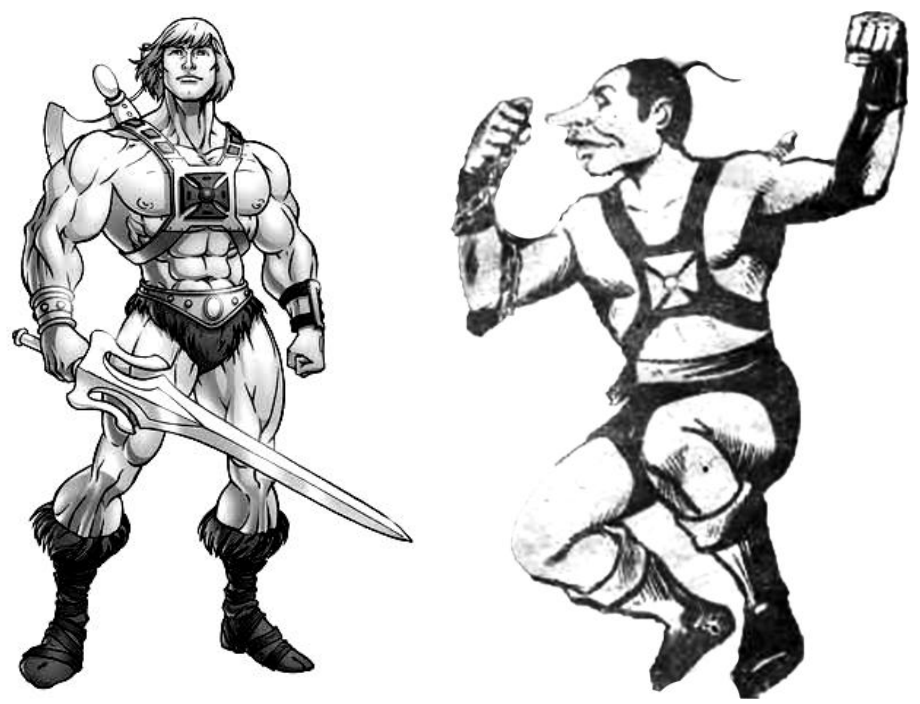

Tak jauh berbeda dari He-Man asal Amerika musuh yang dihadapi Petruk si He-MAN Tumaritis juga merupakan sebuah pasukan kejahatan dan atribut yang dikenakan Petruk digambarakan mirip dengan versi asalnya.Meski memiliki simbol- simbol yang serupa dalam komik Tatang tetap menampilkan jati dirinya. Alur cerita yang sederhana dimainkan dengan para tokoh utama punakawan yaitu Petruk dan Gareng yang bertempat tinggal di kampung Tuamritis maka nama He-Man tidak begitu saja diambil melainakan diberi label Tumaritis yang dapat menjadi pembeda dua tokoh tersebut dan ejaannya disesuakan dengan llidah orang Indonesai yaitu menjadi Hi-Man.

Cerita tersebut menggambarkan Petruk yang berperan sebagai aktan Penolong yang berfungsi sebagai penolog subjek Gareng yang ingin menyelamatkan kekasihnya dari para pasukan kejahatan tersebut.Dengan adanya kekuatan super yang dimilki Petruk maka semua masalah dapat diselesaikan. Petruk digambarkan sebagai manusia dengan kekuatan super yang gagah berani

\section{Komedi Sebagai Pelepas Ketegangan Kelas Bawah}

Pada dasaranya tokoh punakawan dalam pewayangan Jawa selain berfungsi mengawal para ksatria mereka hadir untuk menyegarkan susana dari ketegangan. Maka pada babak kemuncul Punakawan dalam seri pewayangan unsur- unsur komedi sering dimainkan untuk memancing gelak tawa dan sekaligus memunculkan amanat dan kritik di tengah krisisnya dunia.Pada tokoh punakawan dalam komik- komik Tatang suhenra, meski 
jalan ceritanya bertema horor ataupun drama kelucuan mereka selalu disisipakan pada cerita.

Dalam komik Tatang tokoh karikatural mengingatkan dengan ciri punakawan dalam wayang kulit yaitu hidung gareng yang bulat seperti bola, Petruk berhidung panjang, Semar dengan jambulnya dan Bagong dengan mata besarnya. Namun dalam komik ini mereka hadir dengan atribut yang berbeda.Menyesuaikan dengan kondisi maasyarakat kotemporer dengan pakaian lengkap sesuai dengan wacana kehidupan sehari-hari.

Punakawan versi Tatang memang telah meninggalkan identitas punakawan dalam wayang. Tapi dalam model baru yang ditawarkan Tatang Punakwan tetap menjadikan humor sebagai tujuan dalam cerita, seperti yang sering dipertontonkan dalam babak Garagara dalam pertunjukan wayang yang berfungsi sebagai pemecah ketegangan dan mempertontonkan unsur kelucuuan.

Dalam dunia urban tempat komik ditumbuhkan sebagai wahana, kelucuan atau humor itulah yang paling dibutuhkan dari punakwan.Tentu karena komik memang tidak menjadi bacaan kaum intelektual, yang tugasnya adalah berpikir dengan kapasitas penuh, melainkan kelas pekerja yang sangat membutuhkan hiburan ringan pada waktu luangnya di tengah ketegangan hidup di perkotaan. Dari latar dunia agraris feodal berpindah berkatar dunia urban yang menguak hirarki sosial tradisi feodal itu, faktor nasehat yang menjadi ciri lain punakawan agaknya menjadi kurang dibutuhkan dibanding faktor kelucuannya.

Humor yang ditawarkan dalam cerita dalam bebrapa cerita ditunjukan dengan permainan kata- kata.Dalam kategori lelucon yang dibuat Sigmund Freud adalah termasuk pada kategori Lelucon lugu. Contohnya dalam bagian akhir cerita Hi-Man Adu Jotos yaitu Tokoh Petruk berujar, "Itu die Si Garong eh Si Gareng Masih nungguin di situ!" Pada kalimatnya Petruk menyematkan nama yang salah dari Gareng menjadi Garong.

Humor dalam komik- komik Tatang masih menjadi salah satu tujuan yang sering kali ditampilkan seperti pada cerita berjudul "Salah Paham" misalnya, terdapat satu adegan ketika Gareng sedang buang air besar tiba- tiba celananya terbang begitu saja dan Gareng harus mengejar celanya yang terbang hingga wajahnya membentur batang pohon.

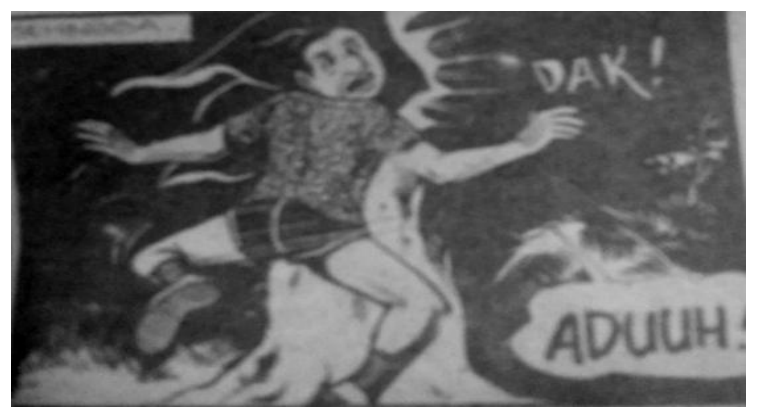

Pada panel tersebut diperlihatkan bagaimana Gareng menjadi objek yang dikerjai oleh sesosok setan hingga pada klimaksnya wajah Gareng yang terbentur batang sebauh pohon.Bentuk kekerasan fisik dan bahkan penderitaan yang dialami Gareng menjadi pantas untuk ditertawakan. Selanjutnya masih pada judul cerita yang sama, Peristiwa penderitaan akibat aksi kejahilan sesosok hantu kembali dipertontonkan untuk memunculkna efek kelucuan. Kali ini Petruk dan Gareng seolah "diadu" oleh hantu pengganggu tersebut. Digambarkan Petruk dan Gareng kemudian saling memukul dan adegan per adegan 
dipertontonkan dengan ekspesi penderitaan dari masing- masing tokoh seperti pada gambar 4.38 .

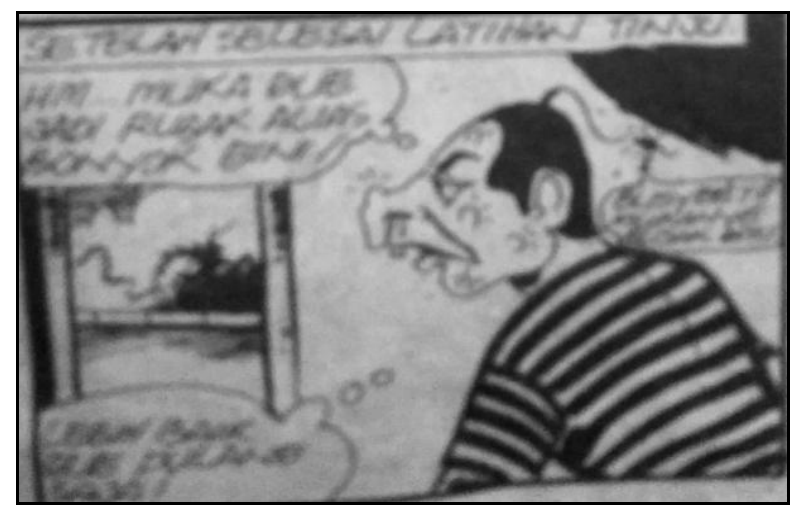

Identitas komedi yang tersuguhkan pada tokoh Punakawan dalam komik Tatang memang bergeser dari tokoh punakawan dalam wayang.Di dalam wayang tokoh punakawan hadir sebagai pengasuh ksatria, yang juga sebagai representasi rakyat jelat namun sekaligus penjelmaan dari dewa.Mereka hadir dan mengambil peran bukan hanya sebagai pelawak namun dalam humornya yang kritis dan penuh dengan amanat. Dalam komik Tatang para punakawan tidak lagi berperan secara ideologis mereka justru hadir dengan unsur fungsi yang berbeda sama sekali. Di dalam komik idelogi humor seperti dihilangkan unsur kritisnya dan hanya menyisakan humor belaka.

Komedi yang disuguhkan dalam komik tersebut merupakan jenis komedi Slapstick yaitu jenis komedi fisik yang mudah dicerna dan bermain dalam lingkup yang luas dan mencakup tiga hal utama yaitu derita, celaka dan aniaya. Komedi Slapstick biasanya lebih mengandalkan kelucuan gerak adegan ketimbang dialog atau monolog yang dibangun pemainnya. Jenis Komedi tersebut komik- komik karya Tatang berusaha memancing tawa melalui konvensi humor seperti kejutan, inivasi dan pelanggaran aturan, melalui humor yang bersifat slapstick yag membuat tubuh babak belur, ketika tawa diharapakan datang dari kesialan orang lain. Jenis komedi semacam itu merupakan humor yang berselera rendah karena mudah dicerna tanpa perlu tingkat kecerdasan tertentu untuk menangkap kelucuannya.Hal tersebut amat identik dengan ciri selera komedi kelas bawah yang penuh kekerasan dan vulgar sebagai pemecah ketegangan ditengah kehidupan kelas pekerja yang membutuhkan pengalihan masalah pada hiburan ringan.

Secara eksplisit komik Tatang merupakan sebuah komik humor yang kelucuannya seperti dirujukan kepada wacana dunia kriminal kelas bawah yang vulgar, tempat kesakitan bahkan penderitaan orang lain diandaikan pantas menjadi bahan tertawaan. Dalam teori superioritas Seno Gumira Ajidarma menjelaskan pendekatan humor semacam itu memang tersahihkan, tetapi disebutkan sebagai alternatif pilihan yang paling akhir (Seno Gumira Ajidarma, 2012:356). 
Arkhais, Vol. 07 No. 2 Jufi - Desember 2016

\section{KESIMPULAN}

Data yang ditemukan berupa dialog antar tokoh dan balon ekspresi dalam balon kata, narasi yang menjelaskan pada tiap panel, closure, efek gerak, tokoh- tokoh yang membangun cerita, dan latar belakang yang menggambarakan latar tempat, waktu dan keadaan yang mampu menggambrakan suasana disekitar tokoh sekaligus mendukung cerita pada komik karya Tatang Suhenra.Berdasarakan hasil analisis semiotik Rolland Barthes ditemukan Teks yang merujuk pada makna denotasi, konotasi dan mitos yang terdapat dalam komik karya Tatang Suhenra. Representasi kelas bawah terdapat pada cerita hantu sebagai simbol kelas bawah yang tergusur, kisah asmara sebagai penanada posisi kelas bawah dalam hierarki kelas, kisah kepahlawanan sebagai sikap moral kelas bawah, komedi yang digunakan sebagai pelepas ketegangan kelas bawah.

\section{DAFTAR RUJUKAN}

Ajidarma, Seno Gumira. 2012.Antara Tawa dan Bahaya. Jakarta: Kepustakaan Populer Gramedia.

. 2011. Panji Tengkorak: Kebudayaan Dalam Perbincangan, Jakarta: Kepustakaan Populer Gramedia.

Alkatiri, Zeffry. 2010. Pasar Gambir, Komik Cina \& Es Shanghai: Sisik Melik Jakarta 1970-an, Jakarta: Masup Jakarta (Komunitas Bambu).

Bal, Mieke. 1997. Narratology: Introduction to the Theory of Narrative, Second Edition. Toronto: University of Toronto Press.

Barthes, Roland. 2011. Mitologi, Bantul: Kreasi Wacana.

Boneff, Marcel, 1998. Komik Indonesia, Jakarta: KPG dan Forum Jakarta Paris.

Echols, John M. dan Hasan Sadily, 1993.Kamus Inggris- Indonesia, Jakarta: Gramedia.

Emzir \& Saifur Rohman. 2015. Teori dan Pengajaran Sastra, Jakarta: Raja Grafindo Persada.

Haryanto, S. 1992. Bayang- bayang Adiluhung: Filsafat, Simbolis dan Mistik dalam Wayang, Semarang: Dahara Prize.

Ridho,Irsyad. 2012. Hibah Buku Ajar Universitas Negeri Jakarta: Teori Sastra, Belum diterbitkan.

- Pengantar Naratologi: Panduan Praktis untuk Mengkaji Sturktur Cerita dan Idologi Cerita, Belum Diterbitakan.

Giles, Judy. 2008. Studying Culture: A Practical Introduction, Wiley-Blackwell. 
Arkhais, Vol. 07 No. 2 Jufi - Desember 2016

Kasiyan. 2008. Manipulasi dan Dehumanisasi Perempuan dalam Iklan. Yogyakarta: Penerbit Ombak.

Kusno, Abidin. 2009. Ruang Publik, Identitas, dan Memori Kolektif: Jakarta PascaSoeharto, Yogyakarta: Penerbit Ombak.

McCloud, Scott. 1993. Understanding Comics :The Invisible Art, Jakarta: Kompas Gramedia.

Prasentyatoko, A. 1999.Kaum Profesional Menentang Rezim Otoriter. Jakarta: Grasindo.

Setiawan, Muhammad Nashir.2002. Menakar Panji Koming : Tafsiran Komik Karya Dwi Koendoro pad Maas Reformasi 1998, Jakarta: Kompas.

Soekanto, Soerjono. 1990.Sosiologi Suatu Pengantar, Jakarta: Raja Grafindo Persada.

Weber, Max. 2006. Studi Komprehensif Sosiologi Kebudayaan, Jogjakarta: IRCiSoD.

Wibowo, Paul Heru. 2012. Masa Depan Kemanusiaan: Superhero dalam Pop Culture. Jakarta: LP3ES.

-------, 2015.Si Jampang Jago Betawi: Kajian Tokoh dalam Komik Ganes TH. Jakarta: Kompas. 